\title{
The systolic murmur in hypertrophic obstructive cardiomyopathy and the nature of the obstruction
}

\author{
M. Nellen \\ M. S. Gotsman \\ Cardiac Clinic, Department of Medicine, Groote Schuur Hospital, \\ and Council for Scientific and Industrial Research Cardiovascular-Pulmonary Research Group, \\ Department of Medicine, University of Cape Town
}

Patients with hypertrophic obstructive cardiomyopathy present with dyspnoea, angina pectoris, palpitations, fatigue or syncope, but the systolic murmur should draw attention to the condition. The murmur begins after the first heart sound, has a crescendo-decrescendo configuration and has its maximum intensity to the right of the mid-systolic point. It is best heard in the fourth left intercostal space, radiates to the apex and base of the heart and has a harsh, low-pitched quality. It varies in intensity from moment to moment-occasionally it is loud, at other times it may be soft or absent. Other notable features on auscultation are the striking fourth heart sound, a softer third heart sound, left and right-sided mid-diastolic flow murmurs due to inflow obstruction and occasionally paradoxical or partial paradoxical splitting of the second heart sound due to prolonged left ventricular ejection. An aortic early diastolic murmur is occasionally heard and may be due to distortion of the aortic valve ring by asymmetrical hypertrophy (Braunwald et al., 1954a, b ; Tucker et al., 1966 ; Goodwin, 1967).

We do not know whether the hypertrophy or gradient in the cases where right ventricular involvement has been described either alone or with left ventricular disease is sufficient to cause a systolic murmur within the right ventricular system, but this is probable. In a recently described case of apparently purely right ventricular involvement, a harsh loud ejection systolic murmur was heard best at the left sternal border and apex (Falcone, Moore \& Lambert, 1967). However, even though no left ventricular gradient was found there may have also been involvement of the left ventricle which may become more apparent in the future. The apical site of the murmur would, however, suggest a left ventricular origin of the murmur even in this case.

While the systolic murmur may occur at a time when there is no pressure gradient as shown by intraventricular phonocardiogram (Goodwin, 1967), the intensity of the murmur appears from our studies to vary with the gradient. That the increase in gradient is associated with increase in systolic murmur intensity does not exclude mitral incompetence as the cause of the murmur because the hypertrophy of the septum and papillary muscle cause both the gradient and mitral incompetence. Mitral insufficiency almost invariably accompanies hypertrophic obstructive cardiomyopathy (Wigle, Marquis \& Auger, 1967) However, we agree with Goodwin (1967, 1968) that there are probably several reasons for the systolic murmur in hypertrophic obstructive cardiomyopathy. Thus obstruction within the left ventricle, mitral incompetence and probably turbulence within the strongly and rapidly contracting ventricle may all play a part in its production.

We have shown that amyl nitrite markedly diminishes the regurgitant murmur of rheumatic valvar mitral incompetence and that phenylephrine intensifies the murmur (Vogelpoel et al., 1959 ; Beck et al., 1961). Amyl nitrite intensifies the systolic murmur in hypertrophic obstructive cardiomyopathy (Nellen et al., 1965) and increases the gradient (Wigle et al., 1964) and phenylephrine abolishes or markedly reduces the murmur and gradient; isoproterenol increases the gradient and murmur (Nellen et al., 1965). These findings do not rule out incompetence of the mitral valve (Fig. 1) as a factor in the production of the systolic murmur. The cause of the mitral incompetence in hypertrophic obstructive cardiomyopathy is papillary dysfunction due to papillary and septal hypertrophy and not a pure valve mechanism. These drugs by altering the internal diameter and mechanics of the obstructive hypertrophy in the left ventricular chamber affect the murmur in opposite directions to their effect in pure valvar mitral incompetence. 
Further support for the view that the obstruction causes the mitral incompetence is that pharmacological abolition of the stenosis also abolishes the mitral incompetence (Wigle et al., 1967).

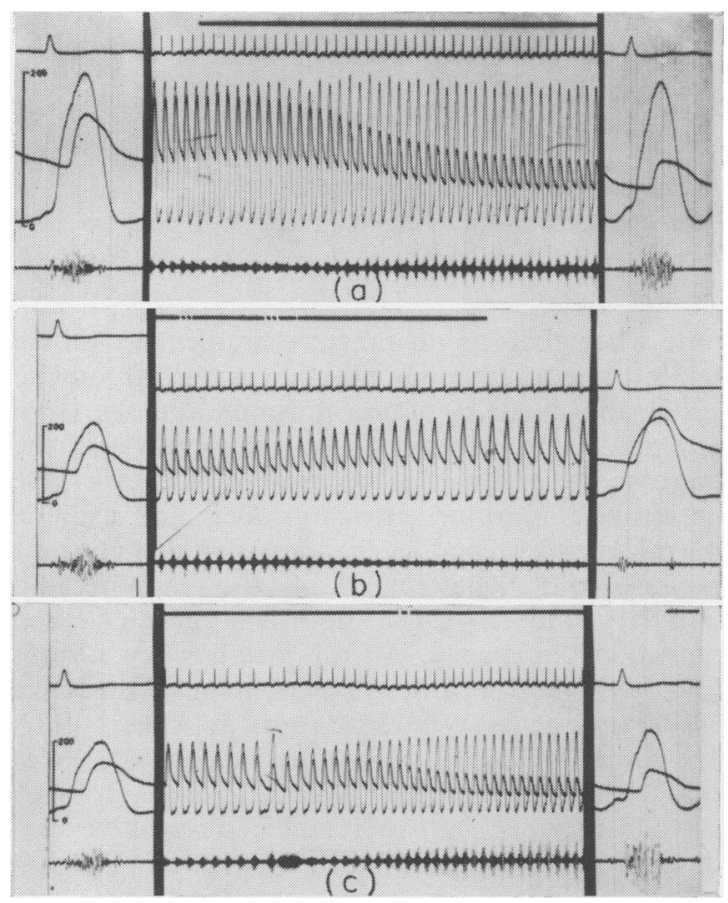

FIG. 1. Hypertrophic obstructive cardiomyopathy. The systolic murmur reflects the haemodynamic situation with (a) amyl nitrite, (b) phenylephrine and (c) isoprenaline. Pressure measurements in left ventricle and femoral artery. Simultaneous external phonocardiogram shown in lower channel.

In contrast to the marked lessening in intensity or disappearance of the systolic murmur in hypertrophic obstructive cardiomyopathy with intravenous phenylephrine we have shown that the murmur of aortic stenosis is hardly affected. It usually lessens only slightly but may actually intensify-this may be a useful bedside test as the two conditions may mimic each other (Nellen et al., 1965) (Fig. 2).

The studies of Marcus, Perloff \& DeLeon (1964) and Hancock \& Fowkes (1966) show that inhalation of amyl nitrite is more useful than isoproterenol as a provocative test for hypertrophic obstructive cardiomyopathy. Inhalation of amyl nitrite has a greater effect than intravenous injection of $2 \mathrm{mg}$ of isoproterenol, is more readily administered, has a briefer action and is less likely to induce adverse effects such as ventricular arrhythmias.
The effect of prompt squatting on the systolic murmur

Prompt squatting provides a simple bedside method of acutely increasing venous return, $c$ effective filling pressure of the heart, stroke output and systemic arterial pressure and resistance (Sharpey-Shafer, 1955).

We have therefore studied the effect of this manoeuvre on the systolic murmur in twelve patients with hypertrophic obstructive cardiomyopathy (Nellen et al., 1967), and we have is compared the effect of this manoeuvre in eight $\vec{\circ}$ patients with fixed valvar aortic stenosis and in five patients with mitral valvar incompetence as the systolic murmurs in these cases may resemble that of hypertrophic obstructive cardiomyopathy.

In hypertrophic obstructive cardiomyopathy we found that this manoeuvre abolished the murmur in three, and softened it markedly in seven. In one, the murmur softened slightly and in one the effect was variable (Figs. 3 and 4). In no case did the murmur intensify. In all the cases of valvar aortic stenosis and mitral incompetence the systolic murmur increased in loudness. To help in the assessment of the mechanism of squatting we studied the effect of this procedure on the murmur of pulmonary steno $_{\infty}$ sis. The systolic murmur in this condition alse quickly intensified on squatting. In this condition. the increase in mean arterial pressure and if peripheral arterial resistance would not be ex:pected to increase the murmur, whereas increase in venous return and effective cardiac

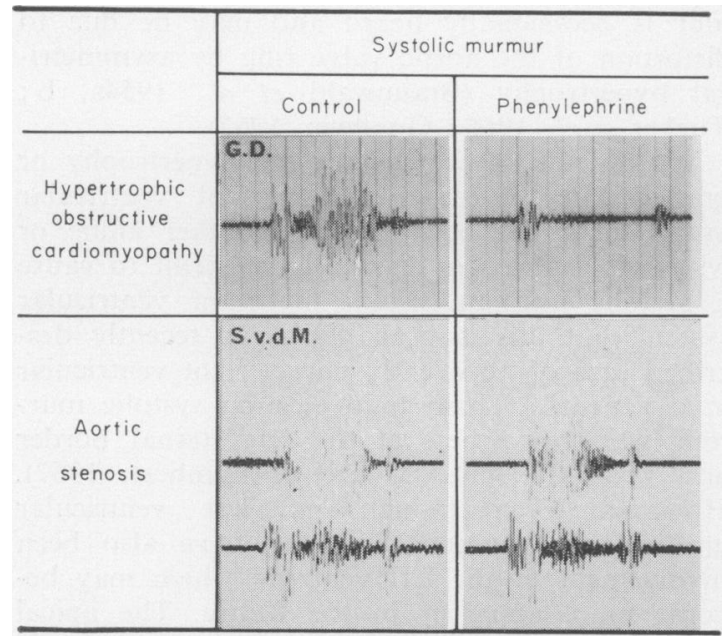

FIG. 2. Phenylephrine virtually abolishes the systolic murmur in hypertrophic obstructive cardiomyopathy, and only slightly affects the murmur an aortic valvar stenosis. 


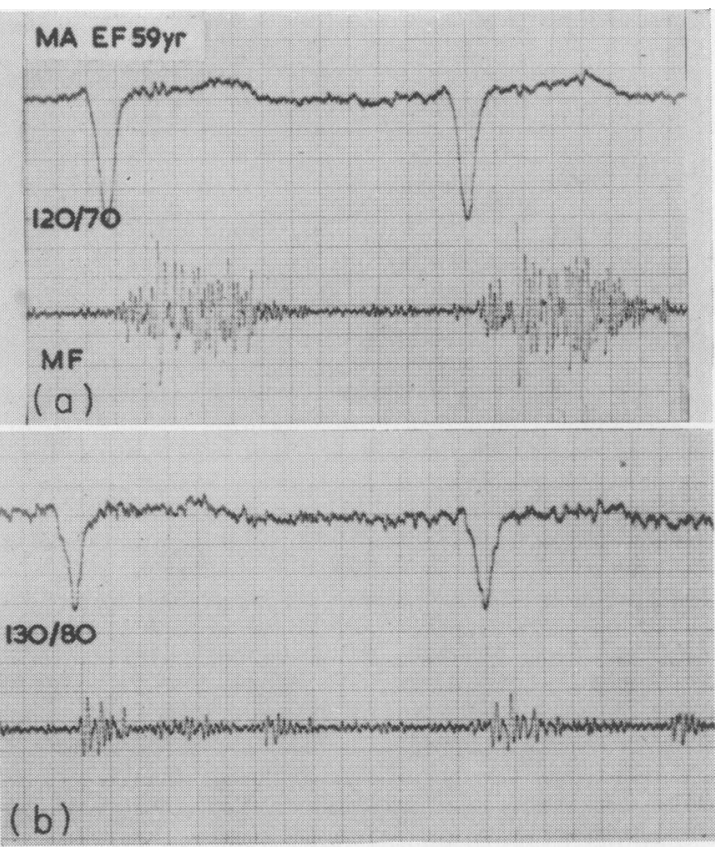

FIG. 3. Hypertrophic obstructive cardiomyopathy: (a) standing, and (b) squatting. Phonocardiogram (MF = medium frequency) taken medial to the apex. The systolic murmur is virtually abolished on squatting. (Lead V1 of the electrocardiogram is indicated in the top tracing. Each large square on the record indicates 0.05 sec.)

filling pressure would do so. The same mechanism would apply to the increase of systolic murmur in valvar aortic stenosis and mitral valvar incompetence. In the latter, increased peripheral resistance could be an added factor.

The increase in intensity of the systolic murmur in hypertrophic obstructive cardiomyopathy can be explained by increased venous return leading to increased left ventricular filling and increase in end-diastolic volume-an effect similar to a rapid infusion of blood or tilting the patient into a head-down position (Braunwald et al., 1964a, b; Shah et al., 1965; Mason, Braunwald \& Ross, 1966). With larger intra-

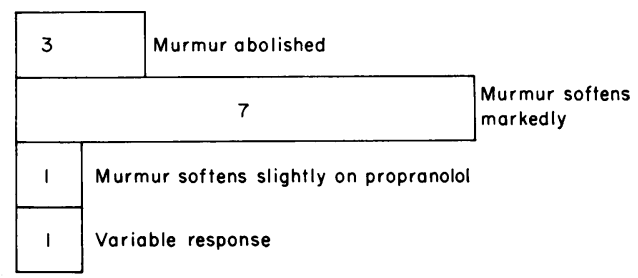

FIG. 4. Effect of squatting on the murmur of hypertrophic obstructive cardiomyopathy in twelve patients. ventricular volume, the gradient lessens due to the increase in ventricular dimension which reduces the degree of obstruction. Additionally the raised arterial pressure and peripheral resistance, the bradycardia and reduction of left ventricular contractility would reduce the gradient and thus the intensity of the murmur.

\section{The nature of the obstruction}

Braunwald et al. (1964a, b) attributed the haemodynamic findings and the murmur to obstruction of left ventricular outflow; Goodwin (1964) broadened the concept and added impedance to inflow in the right and left ventricle as a cause of the diastolic murmurs. Criley et al. (1965) questioned obstruction to the outflow region and suggested that the hourglass silhouette observed at angiocardiography is a diastolic event due to inflow of non-opaque blood from the left atrium. They proposed that the high ventricular pressure gradients resulted from sustained contraction and absence of flow in obliterated portions of the left ventricular cavity. The hypertrophied ventricle empties more completely and faster than the unobstructed normal ventricle, with marked apical obliteration. They also suggested that the systolic murmur is due to mitral incompetence from abnormal alignment of the papillary muscles in the greatly hypertrophied left ventricle.

Ross et al. (1966) showed the presence of definite outflow-tract obstruction during systole, $70 \%$ of the systolic blood volume is ejected during a period when a gradient is present, whilst $30 \%$ of the forward stroke volume is ejected early when no significant pressure gradient is present. These workers showed that isometric pressure development and early ventricular ejection proceed more rapidly than normally, this early systolic period being responsible for the sharp upstroke of the arterial pulse. These workers have thus prepared a strong brief in support of the postulate that an obstructive factor exists in the haemodynamic hypertrophic left ventricle syndrome.

The studies of Wigle et al. (1967) support the views of Ross et al. (1966). These authors stress the importance of the outflow tract as being the site of obstruction in hypertrophic obstructive cardiomyopathy and show by retrograde and trans-septal catheterization that the obstruction is caused by systolic apposition of the ventricular septum and anterior leaflet of the mitral valve. They show how an abnormally high pressure at the apex of the ventricular chamber can be obtained by 'imbedding' or 'catheter entrapment' in various conditions including hypertrophic ob- 
structive cardiomyopathy (Wigle et al., 1967 ; Cross \& Salisbury, 1963; Martin, Hackel \& Sieker, 1963 ; DeBono, Proctor \& Brock, 1965 ; Martin et al., 1965 ; White, Lewis \& Criley, 1965 ; Morrow et al., 1965 ; Tobin et al., 1965 ; Wilson et al., 1967). In these latter conditions (except for hypertrophic obstructive cardiomyopathy) the inflow tract pressure will equal the aortic pressure whereas in hypertrophic obstructive cardiomyopathy the pressure is higher in the inflow tract than in the outflow tract and aorta.

\section{Conclusions}

There are probably several reasons for the systolic murmur in hypertrophic obstructive cardiomyopathy. Obstruction within the left ventricle, mitral incompetence and turbulence within the strongly and rapidly contracting ventricle may all play a part.

The systolic murmur (and gradient) is abolished or lessens markedly in intensity with intravenous phenylephrine, in contrast to the increase in loudness of the murmur of valvar mitral incompetence and little significant change in fixed valvar aortic stenosis. In hypertrophic obstructive cardiomyopathy amyl nitrite inhalation and intravenous isoproterenol intensify the murmur and the gradient. Amyl nitrite is probably the best provocative test for the diagnosis of the condition-being safer and easier to administer than isoproterenol and having a greater effect than the usual $20 \mu \mathrm{g}$ dose of the latter $\beta$-stimulating catecholamine.

Prompt squatting has proved to be an excellent bedside test in this condition-the systolic murmur never increases but is either abolished or decreases markedly in intensity in most cases, in contrast to the intensification of the systolic murmur of valvar mitral incompetence and fixed valvar aortic stenosis.

The obstruction causes a true gradient within the outflow tract of the left ventricle and interferes also with papillary muscle function, causing in most cases some mitral incompetence The problem of 'entrapment' or 'imbedding' of the catheter in the apex has been referred to.

We would agree that although there is a tremendous amount of information on the condition of hypertrophic obstructive cardiomyopathy 'The citadel holding the ultimate truth of the syndrome, is still to be taken' (Burchell, 1966).

\section{Acknowledgments}

We wish to thank Professor V. Schrive and our colleagues in the Cardiac Clinic, and our laboratory staff for assistance with the catherization procedures, and Dr J. G. Burger, Superintendent of Groote Schuur Hospital, for permission to publish. We acknowledge with thanks the continued financial support of the Council for Scientific and Industrial Research and the City Council of Cape Town.

Figs. 1 and 3 are taken from Nellen et al. (1967) Brit. med. $J$. ii, 340, with permission of the Editor.

\section{References}

Beck, W., Schrire, V., Vogelpoel, L., Nellen, M. \& SWANEPOEL, A. (1961) Haemodynamic effects of amyl $\frac{\bar{\sigma}}{\sigma}$ nitrite and phenylephrine on the normal human circula- $\bar{c}$ tion and their relation to changes in cardiac murmurs. Amer. J. Cardiol. 8, 341.

Braunwald, E., Lambrew, C.T., Rockoff, S.D., Ross, J. ¿ \& Morrow, A.G. (1964a) Idiopathic hypertrophic subaortic stenosis 1. A description of the disease based upon $\overrightarrow{0}$ an analysis of 64 patients. Circulation, 30, 3 (Suppl. No. 4).

Braunwald, E., Oldham, H.N., JR, Ross, J., JR, Linbart, $\vec{\omega}$ J.W., Mason, D.T. \& FORT, L. (1964b) Circulatory response of patients with idiopathic hypertrophic sub- $\frac{\partial}{0}$ aortic stenosis to Nitroglycerin and to the val salva manoevre. III. Circulation, 29, 422.

Burchell, H.B. (1966) Pressure differences and obstruction of left ventricular outflow. (Editorial). Circulation, 34, 556. cं

Criley, J.M., LEWIS, K.B., White, R.I. \& Ross, R.S. (1965) Pressure gradients without obstruction-a new concept of 'hypertrophic subaortic stenosis'. Circulation, 32, 881.

Cross, C.E. \& Salisbury, P.F. (1963) Functional subaortic 은 stenosis produced in animals. Amer. J. Cardiol. 12, 394.

DeBono, A.H., Proctor, E. \& Brock, R. (1965) Dynamic obstruction of the left ventricle. Its production and abolition by drugs in normal animals. Guy's Hosp. Rep. 114, 4.

Falcone, D.M., Moore, D. \& LAMberT, E.C. (1967) Idio- רి pathic hypertrophic cardiomyopathy involving the right $\gtrless$ ventricle. Amer. J. Cardiol. 19, 735.

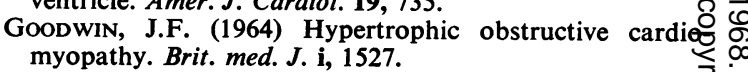

Goodwin, J.F. (1967) Disorders of the outflow tract of the left ventricle. Brit. med. J. ii, 461.

GoodWIN, J.F. (1968) Mitral regurgitation in congestive cardiomyopathy. Postgrad. med.J. 44, 62.

HaNCOCK, E.W. \& Fowkes, W.C. (1966) Effects of amyl nitrite in aortic valvular and muscular subaortic stenosis. Circulation, 33, 383.

Marcus, F.I., Perloff, J.K. \& Deleon, A.C. (1964) Use of amyl nitrite in the hemodynamic assessment of aortic valvular and muscular subaortic stenosis. Amer. Heart $J$. 68, 468.

Martin, A.M., HaCkel, D.B. \& Sieker, H.O. (1963) Intraventricular pressure changes in dogs during hemorrhagic shock. Fed. Proc. 22, 259.

Martin, A.M., JR, HaCKel, D.B., Spoch, M.S., CAPP, M.P. \& MiKAT, E. (1965) Cineangiocardiography in hemorrhagic shock. Amer. Heart J. 69, 283.

Mason, D.T., Braunwald, E. \& Ross, J., JR (1966) Effect of changes in body position on the security of obstruction to left ventricular outflow in idiopathic hypertrophic subaortic stenosis. Circulation, 33, 374.

Morrow, A.G., Vasko, J.S., Henney, R.P. \& Brawley, R.K. (1965) Can outflow obstruction be induced within the normal left ventricle. Amer. J. Cardiol. 16, 540.

Nellen, M., BeCK, W., Vogelpoel, L., Swanepoel, A. \& SCHRIRE, V. (1965) The effect of amyl nitrite, phenylephrine and isoproterenol on the systolic murmur in hypertrophic obstructive cardiomyopathy. S. Afr. med. J. 39, 304.

Nellen, M., Gotsman, M.S., Vogelpoel, L., BeCK, W. \& SCHRIRE, V. (1967) Effects of prompt squatting on the systolic murmur in idiopathic hypertrophic obstructive cardiomyopathy. Brit. med. J. ii, 340.

Ross, J., JR, Braunwald, E., Gault, J.H., Mason, D.T. \& MorRow, A.G. (1966) The mechanism of the intraventricular pressure gradient in idiopathic hypertrophic subaortic stenosis. Circulation, 34, 558. 
Shah, P.M., Amarasingham, R. \& OAkley, C.M. (1965) Haemodynamic effects of changes in blood volume in hypertrophic obstructive cardiomyopathy. Brit. Heart J. 27, 83.

Sharpex-Schafer, E.P. (1955) Effects of squatting on the normal and failing circulation. Brit. med. J. i, 693 .

Tobin, J.R., Blundell, P.E., GoOdrich, R.G. \& Swan, H.J.C. (1965) Induced pressure gradients across infundibular zone of right ventricle in normal dogs. Circulat. Res. $16,162$.

Tucker, R.B.K., Barlow, J.B., Zion, M.M. \& Gale, G.E. (1966) Hypertrophic obstructive cardiomyopathy in Johannesburg. Proceedings, Fifth World Congress on Cardiology, 1966, p. 197.

Vogelpoel, L., Nellen, M., Swanepoel, A. \& Schrire, V. (1959) The use of amyl nitrite in the diagnosis of systolic murmurs. Lancet, ii, 810.
White, R.I., Lewis, K.B. \& Criley, J.M. (1965) Nonobstructive nature of isoproterenol-induced left ventricular pressure gradients in dogs. (Abstract). Circulation, 32, suppl. 11, 11 .

Wigle, D.E., Chrysohou, A. \& Lenkei, S.C.M. (1964) The effect of peripheral vasodilatation in muscular subaortic stenosis. (Abstract). Amer. J. Cardiol. 13, 144.

Wigle, D.E., Marquis, Y. \& Auger, P. (1967) Muscular subaortic stenosis. Initial left ventricular inflow tract pressure in the assessment of intraventricular pressure differences in man. Circulation, 35, 1100.

Wilson, W.S., Criley, J.M. \& Ross, R.S. (1967) Dynamics of left ventricular emptying in hypertrophic subaortic stenosis. Amer. Heart J. 73, 4.

\title{
A modified index of phosphate excretion
}

\author{
B. E. C. Nordin \\ L. Bulusu \\ Medical Research Council Mineral Metabolism Research Unit, \\ General Infirmary, Leeds
}

THERE are several ways of looking at the excretion of phosphorus, or for that matter of any element in the urine. For certain purposes, it is most appropriate to consider the total daily or weekly excretion and relate it to the dietary intake and faecal output as part of a balance study, the object of which is to establish whether the subject is in negative or positive balance on a particular dietary intake. In the study of kidney stone disease, the important criterion is probably the concentration of the different phosphate ion species in the urine and these can be calculated from a knowledge of urinary $\mathrm{pH}$ and total phosphorus concentration (the organic phosphorus content of the urine being negligible). In relation to many other aspects of calcium and phosphorus metabolism, however, the physiological parameter of particular interest is the tubular reabsorption of phosphorus, both because it is a large factor in the regulation of the plasma phosphorus level and because it is under the control of the parathyroid glands.

There are various ways of assessing tubular reabsorption of phosphorus, the simplest being the measurement of phosphate clearance (which Is inversely related to tubular reabsorption) (Kyle, Schaaf \& Canary, 1958) and the most sophisticated the measurement of the maximum tubular reabsorptive capacity (Anderson \& Parsons, 1963). Between these extremes is the phosphate/creatinine clearance ratio which in- dicates the proportion of filtered phosphate that is not reabsorbed by the tubules; it tends to be raised in hyperparathyroidism and reduced in hypoparathyroidism (Milne, Stanbury \& Thompson, 1952 ; Nordin \& Fraser, 1954).

Unfortunately, the phosphate/creatinine clearance ratio is itself governed not only by tubular function but also by the filtered load of phosphorus itself since there is a very high correlation between the plasma phosphorus level and the phosphate/creatinine clearance ratio in normal subjects (Lambert, van Kessel \& Leplat, 1947). For this reason, Nordin \& Fraser (1960) suggested that any particular value of $C_{\mathrm{p}} / C_{\text {or }}$ should always be related to the plasma phosphorus level and that the extent to which the observed value differed from the predicted value could be used as a measure of tubular reabsorption of phosphorus. They called this value the phosphate excretion index, established the limits \pm 0.09 and showed that higher values were associated with states of hyperparathyroidism and low values with states of parathyroid insufficiency.

The general validity of the phosphate excretion index has since been confirmed. It is generally raised in primary hyperparathyroidism (Nordin \& Smith, 1965) and frequently also in the secondary hyperparathyroidism of osteomalacia (Nordin \& Fraser, 1960), renal failure and high phosphate feeding (Smith \& Nordin, 